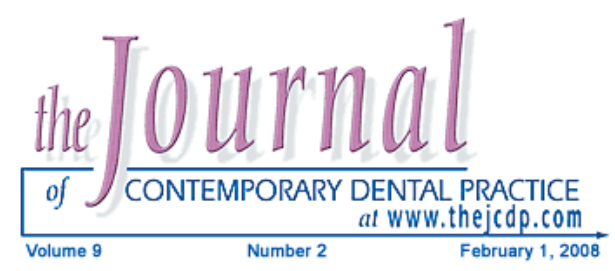

\title{
Influence of Time on Bond Strength After Bleaching with 35\% Hydrogen Peroxide
}

\author{
Cinthia Maria Barbosa, DDS; Robson Tetsuo Sasaki; \\ Flávia Martăo Flório, DDS, MS, ScD; \\ Roberta Tarkany Basting, DDS, MS, ScD, PhD
}

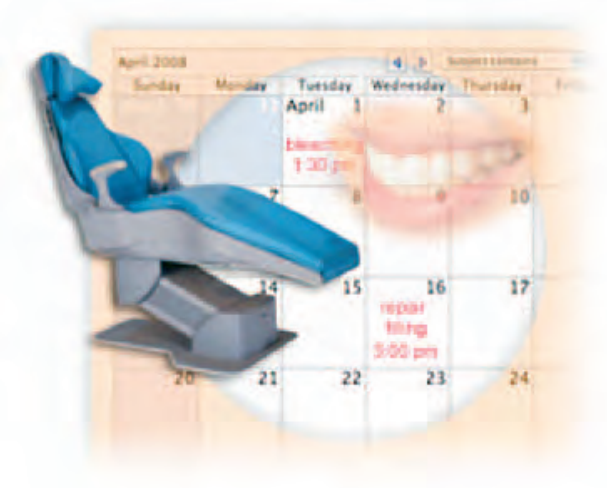

Abstract

Aim: The aim of this in vitro study was to evaluate the influence of time after treatment with a $35 \%$ hydrogen peroxide bleaching agent on the shear bond strength between composite resin and sound enamel and dentin.

Methods and Materials: Eighty dental slabs - 40 enamel (E) slabs and 40 dentin (D) slabs - were embedded, flatted, and divided into four groups $(n=10)$. In $G 1$ the $E$ and $D$ slabs were kept in artificial saliva for 14 days. For the G2, G3, and G4 groups the E and D slabs were submitted to bleaching treatment with a $35 \%$ hydrogen peroxide bleaching agent. At different times after bleaching treatments (G2=immediate; G3=seven days; G4= fourteen days), composite resin cylinders were made using an adhesive system. Tests were performed in a universal testing machine at a speed of $0.5 \mathrm{~mm} / \mathrm{min}$ to obtain the values in $\mathrm{MPa}$.

Results: For enamel, the Kruskal-Wallis test and Dunn Method showed G1 differed significantly from G2 $(\mathrm{G} 1=13.40 \mathrm{a} ; \mathrm{G} 2=6.64 \mathrm{~b} ; \mathrm{G} 3=16.76 \mathrm{a} ; \mathrm{G} 4=11.64 \mathrm{ab}$ ). For dentin, the analysis of variance (ANOVA) and Tukey tests showed that $G 1$ differed significantly from $G 2$ and $G 3$ ( $G 1=12.11$ a; $G 2=4.97$ b; $G 3=8.67 \mathrm{c} ; \mathrm{G} 4=11.86 \mathrm{ac}$ ).

Conclusion: It is recommended adhesive restorative procedures in enamel be delayed for seven days postbleaching treatment with $35 \%$ hydrogen peroxide, while restorations in dentin should be delayed for 14 days following bleaching treatment.

Keywords: Adhesion, bleaching, enamel, dentin, hydrogen peroxide

Citation: Barbosa CM, Sasaki RT, Flório FM, Basting RT. Influence of Time on Bond Strength After Bleaching with 35\% Hydrogen Peroxide. J Contemp Dent Pract 2008 February;(9)2:081-088.

(c) Seer Publishing 


\section{Introduction}

Bleaching and bonding have become a new reality in dentistry, not only because of the availability of new technologies and materials but also as a result of the increase in knowledge and understanding of the mechanism of action of bleaching agents and adhesive systems. The bleaching process is based on the characteristic permeability of hard tissues that form part of the tooth structure. The bleaching agent is applied to the surface of teeth and permeates the tooth tissues, acting at a distance from the location where it was placed. ${ }^{1,2,3,4}$

The action mechanism of bleaching agents is based on a complex oxidation reaction releasing oxygen free radicals that penetrate through the porosities of the enamel prism to the dentin and chemically break down organic molecules that pigment the dentin into carbon dioxide and water released together with the nascent oxygen., This is possible due to the low molecular weight of these substances which is generally $30 \mathrm{~g} /$ mol. ${ }^{1}$ This enables the deep regions of teeth to be bleached even though they are covered by esthetic restorations.

The bleaching agents used in tooth whitening techniques cause oxygen to be released and can cause morphologic alterations in the mineralized structures. ${ }^{8,9,10}$ Alterations on the enamel surface are attributed to the modification of its inorganic composition after treatment with peroxide-based bleaching agents. ${ }^{11}$ These changes in the chemical composition of the enamel considerably diminish the amount of calcium and phosphorous in addition to modifying the morphology of the majority of crystals of the surface layer when compared with enamel not submitted to bleaching. ${ }^{12,13}$ In dentin alterations are also observed due to the presence of residual oxygen that prevents polymerization of the resin.

The reduction in bond strength is important since the presence of oxygen released by the bleaching processes inhibits polymerization of the adhesive systems and is responsible for compromising the bond strength between the restorative material and the dental substrate..$^{13,14,15,16}$ The residual oxygen accumulates not only on the bleached enamel surface but also within the dentinal structure - more precisely on the collagen matrix and in the dentinal tubules. ${ }^{17}$ This may cause difficulties with resin composite ${ }^{3}$ penetration and its polymerization. ${ }^{18}$ Consequently, the reduction in bond strength caused by bleaching agents is related not only to inhibition of resin polymerization due to the accumulation of oxygen on the enamel structure alone but also because of its accumulation within the dentinal structure. ${ }^{13}$

However, this reduction in bond strength after bleaching treatment is time-dependant, and the damage is greater when the bond strength tests are performed immediately after the use of bleaching agents. Nevertheless, bond strength values return to normal after a few days ${ }^{16,19,20}$ when the residual oxygen is liberated, thus, reducing the undesirable effects.

As a result of this phenomenon, it is important to verify the bond strength of composite resin to enamel and dentin as well as the influence of waiting time before performing restorative procedures after in-office dental bleaching treatments are done.

\section{Methods and Materials}

\section{Experimental Design}

The focus of this study was to examine the influence of the time interval between a dental bleaching and restoration of teeth with composite resin that involve enamel and dentin layers of the tooth using the following groups of experimental conditions:

- G1 - Absence of bleaching treatment.

- G2 - Immediate Experiment: Application of treatment with bleaching agent and restoration immediately after the treatment ended.

- G3 - Experiment at seven days: Application of treatment with bleaching agent and restoration after seven days of the treatment ending.

- G4 - Experiment at 14 days: Application of treatment with bleaching agent and restoration after 14 days of the treatment ending.

\section{Preparation of Tooth Slabs}

Completely embedded human third molars stored in a $0.1 \%$ aqueous thymol solution were used to create 80 dental slabs. Forty were enamel (E) slabs and 40 were dentin (D) slabs. The teeth were debrided and polished with a rubber cup along with pumice stone and water at low speed then washed with distilled deionized water. They 
Table 1. Groups and protocols used in the study.

\begin{tabular}{|c|l|l|}
\hline GROUPS & \multicolumn{1}{|c|}{ Enamel } & \multicolumn{1}{|c|}{ Dentin } \\
\hline G1 & Immersion in artificial saliva + Restoration $(n=10)$ & $\begin{array}{l}\text { Immersion in artificial saliva + Restoration } \\
(n=10)\end{array}$ \\
\hline G2 & $\begin{array}{l}\text { Application of } \mathrm{PH} 35 \%+\text { Immediate Restoration } \\
(n=10)\end{array}$ & $\begin{array}{l}\text { Application of } \mathrm{PH} 35 \%+\text { Immediate Restoration } \\
(n=10)\end{array}$ \\
\hline G3 & $\begin{array}{l}\text { Application of } \mathrm{PH} 35 \%+\text { Restoration after seven } \\
\text { days }(n=10)\end{array}$ & $\begin{array}{l}\text { Application of } \mathrm{PH} 35 \%+\text { Restoration after seven } \\
\text { days }(n=10)\end{array}$ \\
\hline G4 & $\begin{array}{l}\text { Application of } \mathrm{PH} 35 \%+\text { Restoration after 14 } \\
\text { days }(n=10)\end{array}$ & $\begin{array}{l}\text { Application of } \mathrm{PH} 35 \%+\text { Restoration after } 14 \\
\text { days }(n=10)\end{array}$ \\
\hline
\end{tabular}

were cross-sectioned to separate them into root and coronal portions then sectioned longitudinally in a mesio-distal direction to obtain the 80 slabs. Those that presented cracks or stains when observed by stereoscopic microscope were excluded from the study. The slab dimensions were $4 \mathrm{~mm} \times 4 \mathrm{~mm} \times 3 \mathrm{~mm}$, presenting a flattened surface area of $16 \mathrm{~mm}^{2}$. The tooth slabs were embedded in polystyrene resin using a PVC mold measuring $2 \mathrm{~cm}$ in diameter, leaving the external enamel and dentin faces uncovered by the resin. After 24 hours, the slabs were removed from the molds and flattened to obtain smooth surfaces for the shear test. Using an Arotec $2 \mathrm{~V} 0$ rotary electrical polisher (Arotec Colombian SA, Bogota, Columbia) the slabs were flattened using decreasing grits $(400,600$, and 1200$)$ of aluminum oxide abrasive papers under a constant water coolant and then polished with diamond pastes. The slabs were randomly distributed among the study groups as shown in Table 1. The test slabs remained immersed in distilled and deionized water in individual receptacles until application of the bleaching agent began.

\section{Bleaching Agent Application}

A commercial brand of whitening gel containing $35 \%$ hydrogen peroxide (Whiteness HP - FGM, Joinville, Brazil) was assessed in this study. A prophylaxis was performed with a rubber cup and pumice on the flattened surfaces of the slabs. Next, the hydrogen peroxide was mixed with the thickener as recommended by the manufacturer and applied to the slabs in Groups G2, G3, and $\mathrm{G} 4$ for ten minutes. The application was repeated three times after rinsing the slabs between each application. After the third application, the Group G2 slabs were immediately set aside and prepared for the shear test.

Groups G3 and G4 slabs remained immersed in an artificial saliva solution in individual receptacles in an oven at $37^{\circ} \mathrm{C}$ for seven days (G3) and 14 days (G4) before the test specimens were made.

Group G1 (control) slabs remained immersed in an artificial saliva solution in individual receptacles in an oven at $37^{\circ} \mathrm{C}$ for two weeks until the test specimens were made for the shear tests. The artificial saliva used was the one described by Featherstone et al. ${ }^{21}$ and modified by Serra and Cury (1996). ${ }^{22}$

\section{Shear Strength Tests}

Test cylinders of Filtek ${ }^{\mathrm{TM}} \mathrm{Z} 250$ microhybrid composite resin (3M, St. Paul, MN, USA) were attached to the dental slabs using the Single Bond $^{\mathrm{TM}}$ adhesive system (3M, St. Paul, MN, USA) in accordance with the manufacturers' recommendations. The composite resin cylinders were prepared by placing adhesive tape with a 2.5 $\mathrm{mm}$ diameter perforation on the tooth slab surfaces to delimit the location for the application of the Single Bond ${ }^{\mathrm{TM}}$ and subsequent attachment of the test cylinders. A Teflon ${ }^{\circledast}$ mold measuring $5 \mathrm{~cm}$ high and $3 \mathrm{~cm}$ diameter was placed over the slab for the application of two layers of resin composite that were light cured for 20 seconds each. The mold was then removed and the specimens were ready for testing. The timing of the tests was as follows:

- Group G2. The shear strength tests were performed immediately.

- Group G3. These specimens were stored in an artificial saliva solution in individual receptacles in an oven at $37^{\circ} \mathrm{C}$ for seven days before the shear strength tests were performed.

- Groups G1 and G4. These specimens remained in artificial saliva for 14 days then were also submitted to the shear strength tests.

The shear tests were performed in a universal test machine (Emic, São José dos Pinhais, Paraná, 
Table 2. Mean of shear strength values of the different groups for enamel.

\begin{tabular}{|c|c|c|c|c|}
\hline & Control (G1) & Immediate (G2) & 7 Days (G3) & 14 Days (G4) \\
\hline Mean & $13.40 \mathrm{a}$ & $6.64 \mathrm{~b}$ & $16.76 \mathrm{a}$ & $11.64 \mathrm{ab}$ \\
\hline Standard Deviation & 2.42 & 1.97 & 3.42 & 5.14 \\
\hline
\end{tabular}

Note: Values followed by equal letters in the vertical do not differ among them according to the Kruskal-Wallis test ( $p>0.05 \%)$.

Table 3. Mean of shear strength values of the different groups for dentin.

\begin{tabular}{|c|c|c|c|c|}
\hline & Control (G1) & Immediate (G2) & 7 Days (G3) & 14 Days (G4) \\
\hline Mean & $2.11 \mathrm{a}$ & $4.97 \mathrm{~b}$ & $8.67 \mathrm{c}$ & $11.86 \mathrm{ac}$ \\
\hline Standard Deviation & 2.81 & 1.74 & 1.96 & 3.47 \\
\hline
\end{tabular}

Note: Values followed by equal letters in the vertical do not differ among them according to the Tukey test $(p>0.05 \%)$.

Brazil) at a speed of $0.5 \mathrm{~mm} / \mathrm{min}$, and the values were obtained in MPa.

\section{Fracture Type Analysis}

After the shear strength tests, the types of fracture on the enamel and dentin surfaces were analyzed by visual exam with the help of a stereoscopic microscope at $30 x$ magnification. The fracture types were classified as follows:

- Adhesive (failure in adhesion)

- Cohesive (failure of the tooth substrate)

- Cohesive in resin (failure of the resin composite)

- Mixed (adhesive and cohesive failures).

\section{Statistical Analysis}

Evaluation of the data in enamel was done with the Kruskal-Wallis non-parametric test for comparison of the experimental groups, using the Multiple Comparisons test (Dunn Method).

Evaluation of the data in dentin was done with the analysis of variance (ANOVA) for comparing the experimental groups, using the Multiple Comparisons test for the individual checks (Tukey Test). The statistical calculations were carried out with use of the Bioestat 3.0 statistical software.

\section{Results}

The results of the shear strength tests for enamel and dentin specimens at different time intervals following the bleaching procedure are presented in Tables 2 and 3, respectively.

There were no significant differences found in the shear strength of enamel between Groups $\mathrm{G} 1$ and $\mathrm{G} 3$ and between $\mathrm{G} 1$ and $\mathrm{G} 4(\mathrm{p}<0.05)$.
For dentin, there were no significant differences between Groups G1 and G4 ( $p<0.05)$. Analysis of the type of fracture for enamel and dentin are presented in Figures 1 and 2, respectively.

\section{Discussion}

The possibility dental bleaching interferes with the bonding of resinous materials to bleached tooth surfaces remains a question. Some in vitro studies report alterations in the chemical and/ or morphological structures of enamel $\left.\right|^{23,24,25,26}$ and dentin. ${ }^{20,27,28}$ Such structural alterations present a diminished shear strength after dental bleaching which may be related to residues from hydrogen peroxide degradation on the tooth surface affecting the polymerization of adhesive systems and resin composites. ${ }^{13,16,19,29,30}$

Use of hydrogen peroxide at high concentrations $(30-35 \%)$ is one of the most common bleaching techniques done in the dental office. The action mechanism occurs through a complex oxidation reaction in which hydrogen peroxide solution with a low molecular weight $(34 \mathrm{~g} / \mathrm{mol})$ is deposited on the tooth enamel and activated by either heat or light radiation depending on the bleaching system used. ${ }^{4}$ The hydrogen peroxide is decomposed into water and nascent oxygen with the latter penetrating rapidly through the enamel porosities and the organic matrix of the enamel and dentin. The oxygen reacts promptly with pigments, possibly causing weak links between the chromatogenic molecules and the organic matrix to rupture. The chromophoric molecules are oxidized by the nascent oxygen ions and are broken down into smaller, less complex and lighter molecules. ${ }^{4}$ 


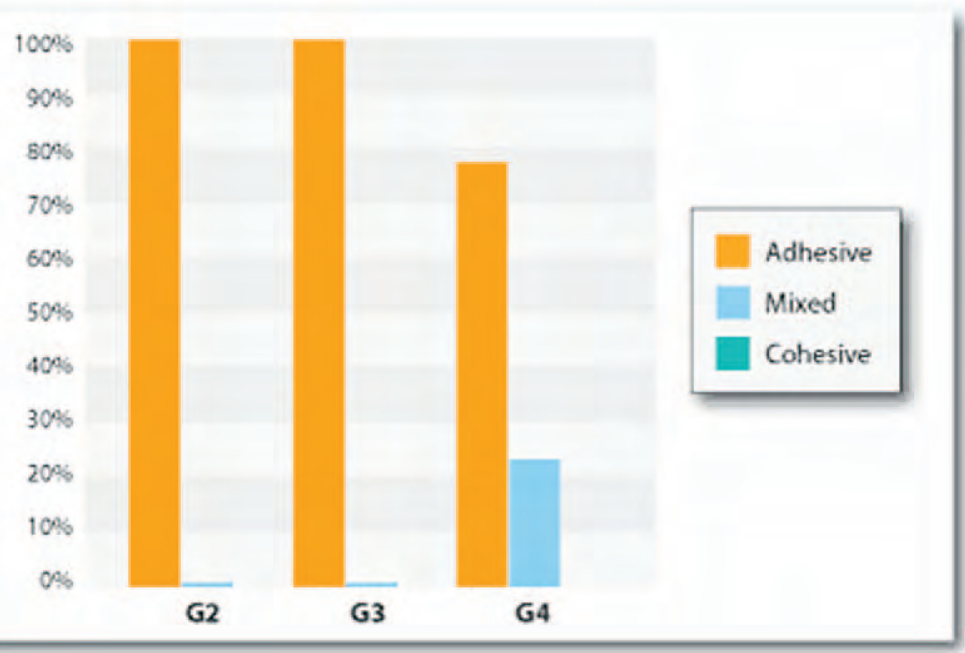

Figure 1. Percentage of fracture type in enamel.

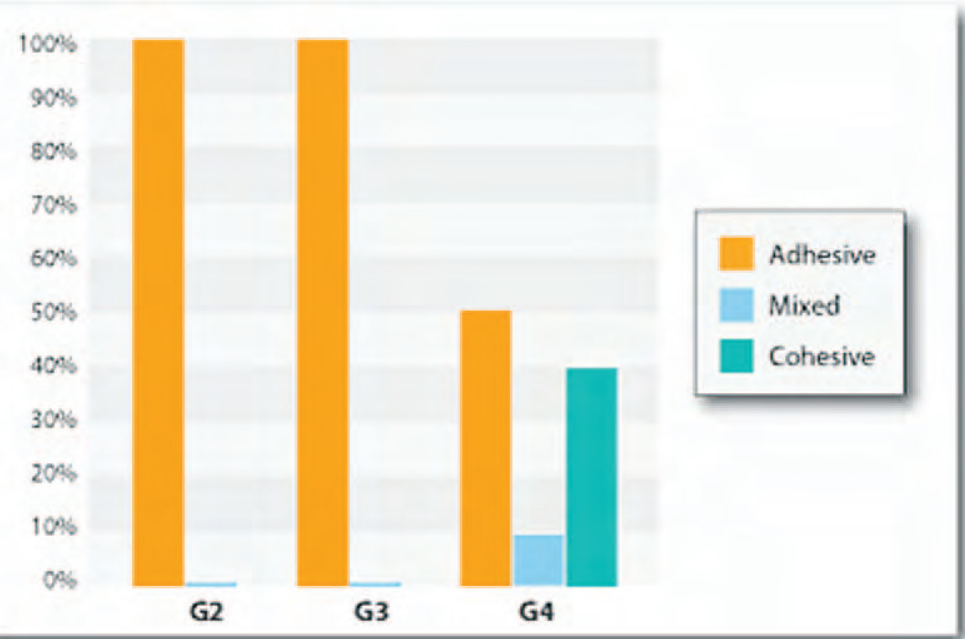

Figure 2. Percentage of fracture type in dentin.

However, Perdigão et al. ${ }^{13}$ found bleaching done with carbamide peroxide did not cause alterations in the relative concentration of oxygen present on the enamel surface, and suggested the oxygen remaining in dentin could be responsible for the reduction in bond strength after bleaching. For these reasons, they recommended immediate restoration with resin composite should be avoided after bleaching to allow time for the residual oxygen on the tooth surface to be eliminated. ${ }^{16}$

Spyrides et al. ${ }^{31}$ suggested dentin could be more affected than enamel after hydrogen peroxide based dental bleaching due to its lower mineral content and the larger quantity of organic matrix.
This may explain the results of the present study in which the dentin specimens required a 14-day post-treatment period after bleaching to be safely restored with composite resin using Filtek ${ }^{\mathrm{TM}} \mathrm{Z250}$ and Single Bond ${ }^{\mathrm{TM}}$. Pergidão et al. ${ }^{13}$ suggested hydrogen peroxide or carbamide peroxide may denature dentin proteins, resulting in alterations to the morphology which could reduce the adhesiveness of composite resin restorations.

Jacobson and Soderholm ${ }^{32}$ suggest the type of solvent used in adhesive systems appears to have an influence on the bond strength of bleached teeth with acetone and ethanol being the two most indicated types of solvents. This may be attributed to the ability of these two 
solvents to carry the hydrophilic monomers of the adhesive system more effectively into dentin tubules, whereas the water-based solvents with a greater presence of humidity may inhibit polymerization. The adhesive system used in this study (Single Bond ${ }^{\mathrm{TM}}$ ) uses ethanol as a solvent. This is in spite of some studies relating its capacity to a reduced surface humidity and an increased shear strength ${ }^{29,33}$ which would appear to have been unable to revert the reduction in the shear strength values, thus, coinciding with the results obtained by Spyrides et al. ${ }^{31}$

The findings of the present study along with those of previous studies provide the dental professional with a fundamental knowledge of a common in-office dental bleaching technique as well as an understanding of how the timing of this technique can influence the outcome of a composite resin restorative procedure. The findings of the present study suggest adhesive composite resin restorations involving only the enamel such as closing diastemas and dental re-anatomization be performed after seven days following in-office (35\% hydrogen peroxide) bleaching, and those involving dentin must be performed after 14 days following an in-office bleaching.
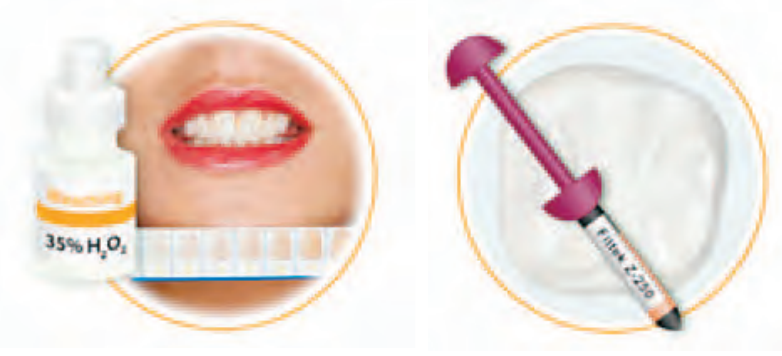

Conclusion

In view of the results obtained, it was found after in-office bleaching treatment with a whitening agent containing $35 \%$ hydrogen peroxide restorations in resin may be performed safely after seven days when they involve the enamel structure and after 14 days when they involve the dentin structure.

\section{References}

1. Cooper JS, Bokmeyer TJ, Bowles WH. Penetration of the pulp chamber by carbamide peroxide bleaching agents. J Endod 1992; 18:315-7.

2. Bowles $\mathrm{WH}$, Ugwuneri Z. Pulp chamber penetration by hydrogen peroxide following vital bleaching procedures. J Endod 1987; 13:375-7.

3. Goldstein CE, Goldstein RE, Feinman RA, Garber DA. Bleaching vital teeth: state of the art. Quintessence Int 1989; 20(10):729-37.

4. McEvoy SA. Chemical agents for removing intrinsic stains from vital teeth. II Current techniques and their clinical application. Quintessence Int 1989; 20(6):379-84.

5. Goldstein GR, Garber DA. Complete dental bleaching. Chicago: Quintessence Books, 1995;165.

6. Haywood VB, Heymann HO. Nightguard Vital Bleaching. Quintessence Int 1989; 20:173-6.

7. Lynch E, Sheerin A, Samarawickrama DY, Atherton MA, Claxson AW, Hawkes J, Haycock P, Naughton D, Seymour KG, Burke FM. Molecular mechanisms of the bleaching actions associated with commercially-available whitening oral health care products. J Ir Dent Assoc 1995; 41(4):94-102.

8. Ben-Amar A, Liberman R, Gorfil C, Bernstein Y. Effect of mouthguard bleaching on enamel surface. Am J Dent 1995; 8:29-32.

9. Lewinsten I, Hirschfeld Z, Stabholz A, Rotstein I. Effect of hydrogen peroxide and sodium perborate on the microhardness of human enamel and dentin. J Endod 1994; 20(2):61-3.

10. Zalkind M, Arwaz JR, Goldman A, Rotstein I. Surface morphology changes in human enamel, dentin and cementum following bleaching: a scanning electron microscopy study. Endod Dent Traumatol 1996; 12:82-8.

11. Hegedüs C, Bistey T, Flora-Nagy E, Keszthelyi G, Jenei A. An atomic force microscopy study on the effect of bleaching agents on enamel surface. J Dent 1999; 27:509-15.

12. McCracken MS, Haywood VB. Demineralization effects of 10 percent carbamide peroxide. J Dent 1996; 24:395-8.

13. Perdigão J, Francci C, Swift EJ, Lopes M. Ultra-morphological study of the interaction of dental adhesives with carbamide peroxide bleached enamel. Am J Dent 1998; 11:291-301. 
14. Titley KC, Torneck CD, Smith DC, Adibfar A. Adhesion of composite resin to bleached and unbleached bovine enamel. J Dent Res 1988; 67(12):1523-8.

15. Cvitko E, Denehy GE, Swift EJ Jr, Pires JA. Bond strength of composite resin to enamel bleached with carbamide peroxide. J Esthet Dent 1991; 3(3):100-2.

16. Titley KC, Torneck CD, Ruse ND, Kmec D. Adhesion of a resin composite to bleached and unbleached human enamel. J Endod 1993; 19:112-5.

17. Nikaido T, Kunzelmann KH, Ogata M, Harada N, Yamaguchi S, Cox CF, Hickel R, Tagami J. The in vitro dentin bond strengths of two adhesive systems in class I cavities of human molars. J Adhes Dent 2002 Spring; 4(1):31-9.

18. Lai SCN, Tay FR, Cheung GSP, Mak YF, Carbalho RM, Wei SHY, Toledano M, Osorio R, Pashley $\mathrm{DH}$. Reversal of compromised bonding in bleached enamel. J Dent Res 2002; 81:477-81.

19. Dishman MV, Covey DA, Baughan LW. The effects of peroxide bleaching on composite to enamel bond strength. Dent Mater 1994;10(1):33-6.

20. Garcia-Godoy, F, Dodge, WW, Donohue M, O'Quinn JA. Composite resin bond strength after enamel bleaching. Oper Dent 1993; 18:144-7.

21. Featherstone JDB, ten Cate JM, Shariati M. Comparision of artificial caries-like lesions by quantitative microrradiographic and microhardness profiles. Caries Res 1983; 17:385-91.

22. Serra MC, Cury JA. The in vitro effect of glass-ionomer cement restorations on enamel subjected to a demineralization and remineralization model. Quintessence int 1992; 23:143-7.

23. Basting RT, Rodrigues Jr AL, Serra MC. The effects of seven carbamide peroxide bleaching agents on enamel microhardness over time. J Am Dent Assoc 2003; 134:1335-42.

24. Josey AL, Meyers IA, Romaniuk K, Symons AL. The effect of a vital bleaching technique on enamel surface morphology and the bonding of composite resin to enamel. J Oral Rehab 1996; 23:244-50.

25. McGuckin RS, Thurmond BA, Qsovitz S. Enamel shear bond strengths after vital bleaching. Am J Dent 1992; 5:216-22.

26. Rodrigues JA, Basting RT, Serra MC, Rodrigues Jr AL. Effects of $10 \%$ carbamide peroxide bleaching materials on enamel microhardness at different time intervals. Am J Dent 2001; 14:67-71.

27. Basting RT, Rodrigues Jr AL, Serra MC. The effect of $10 \%$ carbamide peroxide bleaching material on microhardness of sound and demineralized enamel and dentin in situ. Oper Dent 2001; 26:531-9.

28. Freitas PM, Basting RT, Rodrigues Jr AL, Serra MC. Effects of two 10\% peroxide carbamide bleaching agents on dentin microhardness at different time intervals. Quintessence Int 2002; 33:370-5.

29. Kalili T, Caputo AA, Mito R, Sperbeck G, Matyas J. In vitro toothbrush abrasion and bond strength of bleached enamel. Pract Periodontics Aesthet Dent 1991 Aug; 3(5):22-4.

30. Torneck CD, Titley KC, Smith DC, Adibfar A. The influence of time of hydrogen peroxide exposure on the adhesion of composite resin to bleached bovine enamel. J Endod 1990; 16:123-8.

31. Spyrides GM, Perdigao J, Pagani C, Araujo MA, Spyrides SM. Effect of whitening agents on dentin bonding. J Esthet Dent 2000; 12(5):264-70.

32. Jacobsen T, Soderholm KJ. Some effects of water on dentin bonding. Dent Mater 1995;11(2):132-6.

33. Sung EC, Chan SM, Mito R, Caputo AA. Effect of carbamide peroxide bleaching on the shear bond strength of composite to dental bonding agent enhanced enamel. J Prosthet Dent 1999;82(5):595-9. 
About the Authors

\section{Cinthia Maria Barbosa, DDS}

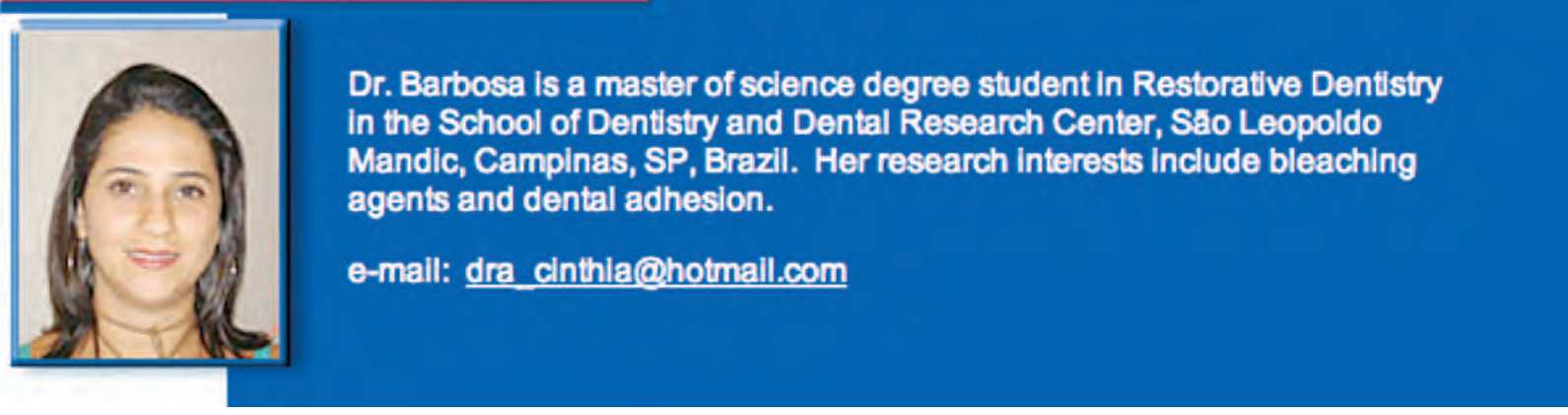

\section{Robson Totsuo Sasaki}

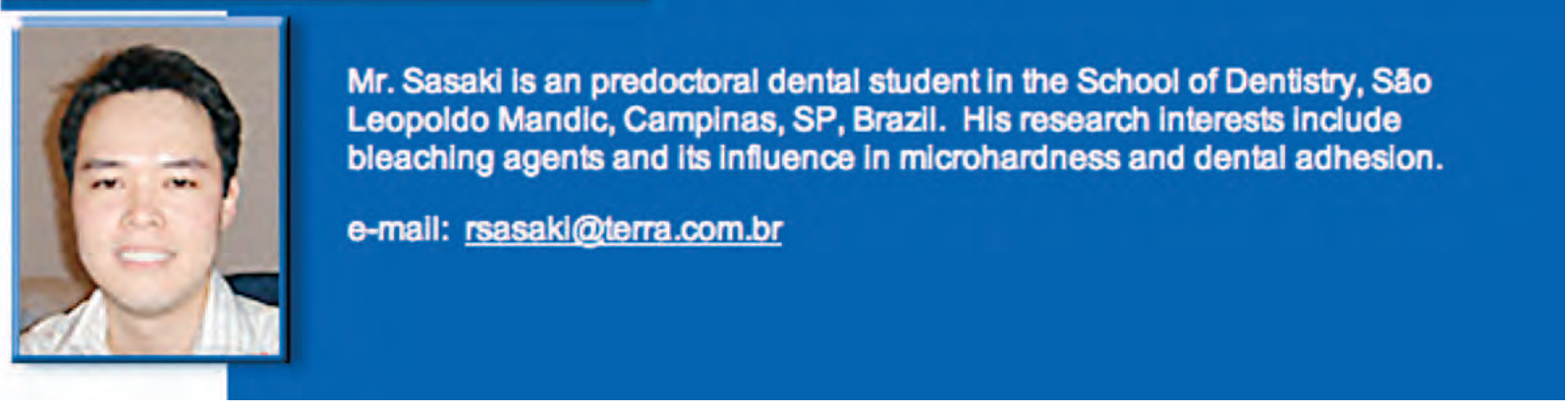

\section{Flávia Martīo Flório, DDS, MS, SeD}

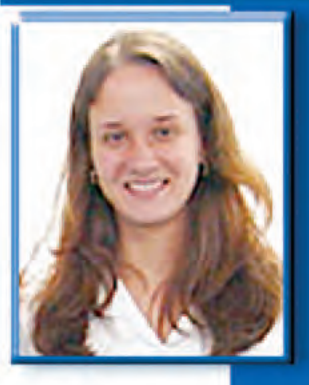

Dr. Fiorio is a Professor in the Department of Preventive Dentistry of the School of Dentistry and Dental Research Center, Sao Leopoldo Mandlic, Campinas, SP, Brazil. Her research Interests focus on preventive dentistry, microblology, and health promotion.

e-mail: flaviafiorio@yahoo.com

\section{Roborta Tarkany Bating, DDS, MS, SeD, PhD}

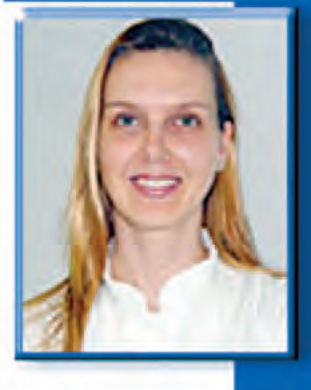

Dr. Basting is a Professor In the Department of Restorative Dentistry of the School of Dentistry and Dental Research Center, Saao Leopoldo Mandic, Campinas, SP, Brazll. Her research Interests focus on bleaching agents, esthetics, cavity preparation, adhesion, and properties of dental materials.

e-mall: rbasting@yahoo.com 